Erratum

\title{
Erratum: Korkovelos, A., et al. The Role of Open Access Data in Geospatial Electrification Planning and the Achievement of SDG7. An OnSSET-Based Case Study for Malawi. Energies 2019, 12(7), 1395
}

\author{
Alexandros Korkovelos 1,*(D), Babak Khavari ${ }^{1}$, Andreas Sahlberg ${ }^{1}$, Mark Howells ${ }^{1,2}$, \\ Christopher Arderne ${ }^{3}$ and Dimitrios Mentis ${ }^{1,4}$ \\ 1 Division of Energy System Analysis, KTH Royal Institute of Technology, Brinellvägen 68, \\ 10044 Stockholm, Sweden; khavari@kth.se (B.K.); asahl@kth.se (A.S.); M.I.Howells@lboro.ac.uk (M.H.); \\ Dimitrios.Mentis@wri.org (D.M.) \\ 2 Department of Geography, Climate Compatible Growth (CCG) Program, Loughborough University, \\ Loughborough LE11 3TU, Leicestershire, UK \\ 3 The World Bank Group, Washington, DC 20433, USA; carderne@worldbank.org \\ 4 World Resources Institute, Washington, DC 20002, USA \\ * Correspondence: alekor@kth.se; Tel.: +46-735-843-613
}

Received: 28 August 2020; Accepted: 15 September 2020; Published: 24 September 2020

The authors wish to make a change in author names (adding new author-Dimitrios Mentis) to this paper [1]:

\section{Author Contributions}

On page 19, author contributions are updated as follows:

Conceptualization, A.K., D.M. and M.H.; Methodology, A.K., A.S., B.K. and D.M.; Software, A.K., B.K., A.S. and C.A.; Validation, M.H.; Formal Analysis, A.K.; Investigation, A.K.; Resources, A.K. and B.K.; Data Curation, A.K., B.K. and A.S.; Writing-Original Draft Preparation, A.K.; Writing-Review and Editing, A.K., D.M., M.H., C.A.; Visualization, A.K. and B.K.; Supervision, M.H.; Project Administration, M.H.; Funding Acquisition, M.H., D.M. and A.K. All authors have read and agreed to the published version of the manuscript.

\section{Funding}

On page 19, funding sources are updated as follows:

This research was funded by the World Bank under the contract number 7185716 and partially by (a) the Swedish Center for Smart Grids and Energy Storage (SweGRIDS-ABB) under grant VF-2015-0018 and (b) the ÅForsk Foundation under grant 17-604.

The authors would like to apologize for any inconvenience caused to the readers and contributors by these changes. The changes do not affect the scientific results. The manuscript will be updated, and the original will remain online on the article webpage, with a reference to this correction.

\section{Reference}

1. Korkovelos, A.; Khavari, B.; Sahlberg, A.; Howells, M.; Arderne, C. The role of open access data in geospatial electrification planning and the achievement of SDG7. An OnSSET-based case study for Malawi. Energies 2019, 12, 1395 .

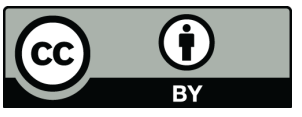

(C) 2020 by the authors. Licensee MDPI, Basel, Switzerland. This article is an open access article distributed under the terms and conditions of the Creative Commons Attribution (CC BY) license (http://creativecommons.org/licenses/by/4.0/). 